\title{
Long non-coding RNA CCAT2 functions as an oncogene in hepatocellular carcinoma, regulating cellular proliferation, migration and apoptosis
}

\author{
NING ZHOU, ZHONGZHOU SI, TING LI, GUANGSHUN CHEN, ZHONGQIANG ZHANG and HAIZHI QI \\ Department of Organ Transplantation and General Surgery, The Second Xiangya Hospital of Central South University, \\ Changsha, Hunan 410011, P.R. China
}

Received April 10, 2015; Accepted April 29, 2016

DOI: $10.3892 / \mathrm{ol} .2016 .4580$

\begin{abstract}
An increasing number of studies have demonstrated that the dysregulation of long non-coding RNAs (lncRNAs) may serve an important role in tumor progression. Previous studies have reported that the lncRNA, colon cancer associated transcript 2 (CCAT2), was highly expressed in various tumors. However, the function of CCAT2 in hepatocellular carcinoma (HCC) has not yet been elucidated. The aim of the present study was to identify novel oncogene lncRNAs and investigate their physiological function and mechanism in HCC. Using reverse transcription-quantitative polymerase chain reaction, it was observed that CCAT2 was upregulated in HCC tissues and human HCC cell lines. Furthermore, the impacts of CCAT2 on cell proliferation, migration and apoptosis were analyzed using cell migration, 3-(4,5-dimethylthiazol-2-yl)-2,5-diphenyltetrazolium bromide and enzyme-linked immunosorbent assay analysis respectively. The overexpression of CCAT2 using a synthesized vector significantly promoted cell migration and proliferation, and inhibited apoptosis of HCC cells in vitro. The suppression of CCAT2 expression resulted in opposing effects. To the best of our knowledge, the present study is the first to demonstrate that CCAT2 functions as a oncogene in HCC. Further investigation is required to clarify the molecular mechanisms of this IncRNA in HCC development.
\end{abstract}

\section{Introduction}

Hepatocellular carcinoma (HCC) is the third most prevalent cause of cancer-associated mortality worldwide, and is one of the most lethal malignancies (1). Currently, HCC is refractory

Correspondence to: Professor Haizhi Qi, Department of Organ Transplantation and General Surgery, The Second Xiangya Hospital of Central South University, 139 Renmin Road, Changsha, Hunan 410011, P.R. China

E-mail: qihaizhimd@163.com

Key words: hepatocellular carcinoma, long non-coding RNAs, CCAT2, upregulated, oncogene to conventional chemotherapies. Early-stage HCC with normal liver function may be effectively treated with liver resection, transplantation or percutaneously, with patients experiencing a considerable 5-year survival rate. However, the majority of patients are diagnosed at later or inoperable stages (2). Generally, the progression of HCC is characterized by numerous aberrant cell behaviors, including the loss of tissue-specific gene expression, a decrease in cell differentiation, an increase in proliferation and the induction of metastasis (3). Patients with HCC frequently present with tumor cell invasion and migration prior to a definite diagnosis $(4,5)$. Therefore, it is imperative to clarify the molecular mechanisms underlying HCC etiology, and develop novel therapeutic agents to successfully treat the disease.

With the development of deep gene sequencing technology, an increasing amount of research is being focused on non-coding RNAs (ncRNAs). ncRNAs are transcribed from the human genome, and include microRNAs (miRNAs), small interfering RNAs (siRNAs), long ncRNAs (lncRNAs) and PIWI-interacting RNAs $(6,7)$. A large number of studies have concentrated on siRNAs and miRNAs, with their functions and molecular mechanisms being elucidated in recent years (8-10). However, the understanding of the functions of lncRNAs in various diseases remains extremely limited. Recent studies have reported that IncRNAs may also serve a key role in transcription, chromatin modification and post-transcriptional processing (11-13).

The number of studies investigating 1 ncRNAs has increased unexpectedly in recent years $(14,15)$. The nuclear-enriched abundant transcript 2, MALAT1, located at human chromosome 11q13, was reported to exhibit high expression in numerous species, and was demonstrated to regulate primary transcripts either transcriptionally or posttranscriptionally $(16,17)$. Lai et al $(18)$ reported that MALAT1 expression was upregulated in HCC tissues and cell lines and functioned as an independent prognostic factor for HCC recurrence. HOX transcript antisense RNA (HOTAIR) was noted as an additional lncRNA involved in cancer migration and metastasis. Ishibashi et al (19) reported that a high expression level of HOTAIR was detected in patients with primary HCC. Patients with high HOTAIR expression consistently exhibit poor prognoses and a low 5-year survival rate. Another 
extensively investigated lncRNA is maternally expressed 3 (MEG3), which serves an important role in regulating growth and cell development. Braconi et al (20) reported that MEG3 was downregulated in HCC tumor tissues. Restoration of MEG3 in HCC cells significantly inhibited cell growth and induced apoptosis.

Deep gene sequencing technology has aided the investigation of various dysregulated lncRNAs in HCC. However, when compared with miRNAs, the current understanding of lncRNAs is limited. Previous studies have demonstrated that colon cancer associated transcript 2 (CCAT2) was upregulated in lung and gastric cancer $(21,22)$, indicating that the lncRNA possesses oncogenic characteristics. The present study aimed to verify the expression level of CCAT2 in HCC tissues and cell lines, and assess the impact of CCAT2 on cell proliferation, migration and apoptosis, with the results demonstrating that CCAT2 functions as a oncogene in HCC.

\section{Materials and methods}

Patients and tissue samples. A total of $50 \mathrm{HCC}$ tissue samples were obtained from 50 different patients between July 2008 and June 2013 from The Second Xiangya Hospital of Central South University (Changsha, China). None of the patients received percutaneous ablation, chemoembolization or radiotherapy prior to surgery. For all patients, paired tumor and non-tumor liver tissue samples were collected immediately following liver resection and were snapfrozen at $-80^{\circ} \mathrm{C}$ until use. The pathological diagnosis was confirmed in all cases by the Department of Pathology, The Second Xiangya Hospital of Central South University. The clinical pathological data of the patients is presented in Table I. The Ethics Committee of The Second Xiangya Hospital of Central South University granted approval for the study prior to sample collection, and the patients or a family member signed a consent form permitting the collection and use of their samples for the present study.

Cell culture and transfection. HCC cell lines (HepG2, HEP3B, HCCLM3 and HuH7) and one normal liver cell line (L02) were obtained from the American Type Culture Collection (Mannasas, VA, USA). The cells were cultured with Dulbecco's modified Eagle's medium (Invitrogen; Thermo Fisher Scientific, Inc., Waltham, MA, USA) supplemented with $10 \%$ fetal bovine serum (Invitrogen; Thermo Fisher Scientific, Inc.). All cells were maintained at $37^{\circ} \mathrm{C}$ in a humidified chamber with $95 \%$ air and $5 \% \mathrm{CO}_{2}$.

CCAT2 small hairpin RNA (shRNA;target sequence, 5'-UUAACCUCUUCCUAUCUCATT-3') were purchased from GeneChem Co., Ltd. (Shanghai, China). The CCAT2 overexpression plasmid, CCAT2-pcDNA3.1(+), was synthesized by Life Technologies (Thermo Fisher Scientific, Inc.). HepG2 and $\mathrm{HuH} 7$ cells were transfected with $2 \mu \mathrm{g}$ of CCAT2 shRNA or CCAT2-pcDNA3.1(+) vector using Lipofectamine ${ }^{\circledR} 2000$ (Invitrogen; Thermo Fisher Scientific, Inc.).

Reverse transcription-quantitative polymerase chain reaction $(R T-q P C R)$. The first-strand cDNA was synthesized using oligo-dT primers from the RevertAid ${ }^{\mathrm{TM}}$ First Strand cDNA Synthesis kit (catalog no., K1621; Thermo Fisher Scientific, Inc.). The primers used were as follows: Human
Table I. Clinical and pathological characteristics of patients with hepatocellular carcinoma.

\begin{tabular}{lc}
\hline Characteristics & Number of patients \\
\hline Age, years & \\
$\leq 50$ & 22 \\
$>50$ & \\
Gender & \\
Male & 37 \\
Female & 13 \\
Tumor size, cm & \\
$\leq 5$ & 27 \\
$>5$ & 23 \\
Clinical TNM stage & \\
I & 7 \\
II & 28 \\
III & 13 \\
IV & 2
\end{tabular}

TNM, tumor-node-metastasis.

CCAT2, forward, 5'-CCCTGGTCAAATTGCTTAACCT-3', and reverse, 5'-TTATTCGTCCCTCTGTTTTATGGAT-3'; and human glyceraldehyde 3-phosphate dehydrogenase (GAPDH), forward, 5'-CCACATCGCTCAGACACCAT-3', and reverse 5'-ACCAGGCGCCCAATACG-3'. GAPDH was utilized as an internal control. RT-qPCR was performed using the $\mathrm{SYBR}^{\circledR}$ Premix Ex Taq ${ }^{\mathrm{TM}}$ II (Tli RNaseH Plus) (catalog no., RR820A; Takara Biotechnology Co., Ltd., Dalian, China) according to the manufacturer's protocol on the Light-cycler $480^{\circledR}$ II Real-Time PCR System (Roche Diagnostics, Basel, Switzerland). The results were normalized using the $2^{-\Delta \Delta \mathrm{Cq}}$ method (23). The conditions for PCR were as follows: $98^{\circ} \mathrm{C}$ for $5 \mathrm{~min}$, followed by 45 cycles of $98^{\circ} \mathrm{C}$ for $10 \mathrm{sec}, 60^{\circ} \mathrm{C}$ for $30 \mathrm{sec}$ and $72^{\circ} \mathrm{C}$ for $30 \mathrm{sec}$. The experiments were performed in triplicate and repeated at least three times.

Cell proliferation assay. Cell growth was analyzed using an MTT assay performed according to the manufacturer's protocol. HepG 2 and HuH7 cells ( $1 \times 10^{4}$ cells) were seeded into a 96-well culture plate $24 \mathrm{~h}$ prior to transfection with CCAT2 shRNA and shRNA negative control, or CCAT2-pcDNA3.1(+) vector and pcDNA3.1(+) empty vector. After $0,24,48$ or $72 \mathrm{~h}$ transfection, $20 \mu 1$ 3-(4,5-dimethylthiazol-2-yl)-2,5-diphenyltetrazolium bromide (MTT; $5 \mathrm{mg} / \mathrm{ml}$; Invitrogen; Thermo Fisher Scientific, Inc.) was added to each plate and incubated for $4 \mathrm{~h}$ at $37^{\circ} \mathrm{C}$. Subsequently, $150 \mu \mathrm{l}$ dimethyl sulfoxide was added to each plate and agitated for $10 \mathrm{~min}$ at $37^{\circ} \mathrm{C}$ in order to solubilize the crystals. The number of cells per plate were measured by the absorbance $(540 \mathrm{~nm})$ at the indicated time points. Assays were repeated at least three times.

Cell migration assay. The 24-well Boyden chamber with $8-\mu \mathrm{m}$ pore size polycarbonate membrane (Corning Incorporated, Corning, NY, USA) was used to evaluate cell motility. HepG2 and HuH7 cells were transfected with CCAT2 
shRNA and negative control, or CCAT2-pcDNA3.1(+) vector and pcDNA3.1(+) empty vector using Lipofectamine 2000. Matrigel (BD Biosciences, San Jose, CA, USA) was used to simulate a matrix barrier for the migration assay. Following $48 \mathrm{~h}$ of transfection, a total of $4 \times 10^{3}$ cells were seeded in the upper chamber with $200-\mu 1$ serum-free medium. A total of $600 \mu \mathrm{l}$ of medium containing $20 \%$ serum, which served as a chemoattractant, was added into the lower chamber. Following $24 \mathrm{~h}$ of incubation, the membranes were fixed with methanol and stained with $0.1 \%$ crystal violet at $37^{\circ} \mathrm{C}$. Three visual fields were randomly selected from each membrane, and the number of cells were counted using a light-microscope. Experiments were run in three independent repeats in triplicate, and were examined in a double-blind manner by at least two observers.

Cell apoptosis assay. At $48 \mathrm{~h}$ post-transfection, apoptosis induced by CCAT2 shRNA and negative control, or CCAT2-pcDNA3.1(+) vector and pcDNA3.1(+) empty vector, was evaluated by calculating the activity of caspase 3 using the Human Caspase 3 ELISA kit (Cusabio, Wuhan, China) and Hoechst 33258 staining (Invitrogen; Thermo Fisher Scientific, Inc.). The results were observed by a Laser Scanning Confocal Microscope (Zeiss AG, Oberkochen, Germany) and analyzed using Image-Pro ${ }^{\circledR}$ Plus 5.1 software (Media Cybernetics Inc, Bethesda, MD, USA). All experiments were performed three times.

Statistical analysis. Statistical analysis was conducted using SPSS 17.0 (SPSS, Inc., Chicago, IL, USA). Statistical significance was determined with Student's t-test. Data are presented as the mean \pm standard deviation. For the comparison of CCAT2 expression levels in matched tumor vs. normal samples, a paired t-test was used. $\mathrm{P}<0.05$ was considered to indicate a statistically significant difference.

\section{Results}

CCAT2 is upregulated in HCC tissues and cell lines. The endogenous expression of CCAT2 in human HCC tissues was compared with adjacent non-cancerous tissues by RT-qPCR. It was observed that the expression of CCAT2 was significantly upregulated in the HCC tissues when compared with the matched normal liver tissue $(\mathrm{P}<0.05$; Fig. 1A). Furthermore, it was demonstrated that CCAT2 expression was significantly higher in all $4 \mathrm{HCC}$ cell lines when compared with that in the normal liver epithelial L02 cells ( $\mathrm{P}<0.05$; Fig. 1B). Collectively, these results suggest that CCAT2 is upregulated in HCC tissues and cell lines.

CCAT2 promotes proliferation of HCC cells. To investigate the potential role of CCAT2 in HCC, the inhibitory effect of CCAT2 on HCC cells was analyzed. HepG2 and HuH7 cell proliferation was measured by MTT assay following transfection with CCAT2 shRNA and negative control, or CCAT2-pcDNA3.1(+) vector and pcDNA3.1(+) empty vector. As expected, transfection of the CCAT2-pcDNA3.1(+) vector into the $\mathrm{HepG} 2$ and $\mathrm{HuH} 7$ cells resulted in a significant increase in CCAT2 expression when compared with the pcDNA3.1(+) empty vector (Fig. 2A), and the transfection of the CCAT2 shRNA into the HepG2 and HuH7 cells resulted in a decrease

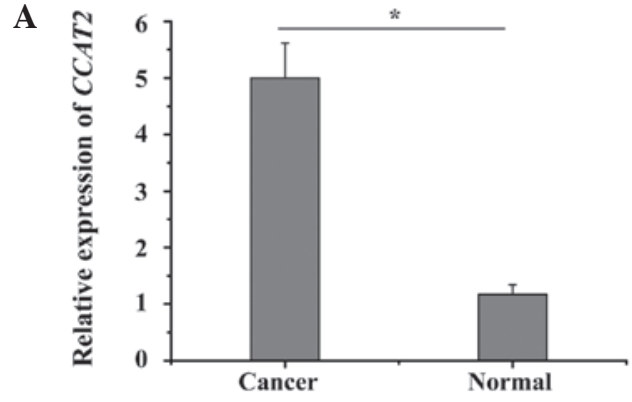

B

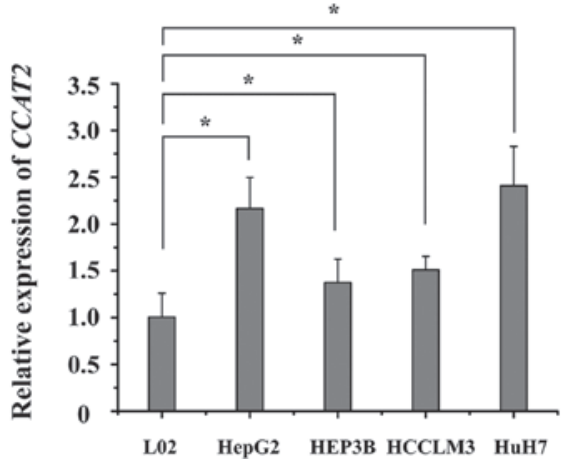

Figure 1. CCAT2 was upregulated in the HCC tissues and cell lines. (A) RT-qPCR analyzed CCAT2 expression relative to GAPDH expression in 50 HCC tissue samples (Cancer) compared with matched non-cancerous liver tissue (Normal). (B) RT-qPCR analyzed CCAT2 expression levels in the HCC HepG2, HEP3B, HCCLM3 and HuH7 cell lines compared with the normal liver L02 cell line. Data are expressed as the mean \pm standard deviation $(n=3)$. ${ }^{*} \mathrm{P}<0.05$. CCAT2, colon cancer associated transcript 2; HCC, hepatocellular carcinoma; GAPDH, glyceraldehyde 3-phosphate dehydrogenase; RT-qPCR, reverse transcription-quantitative polymerase chain reaction.

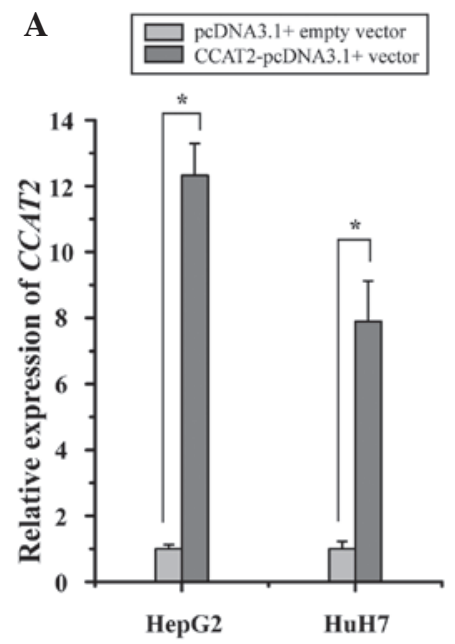

B

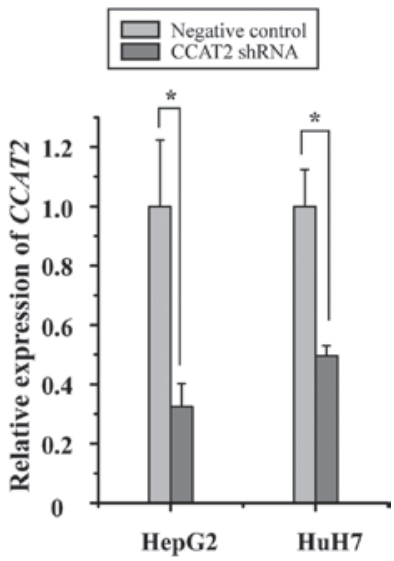

Figure 2. Transfection of CCAT2 shRNA and negative control or CCAT2-pcDNA3.1(+) vector and pcDNA3.1(+) empty vector to HepG2 and $\mathrm{HuH} 7$ cells alters the expression of CCAT2. (A) Transfection of the CCAT2-pcDNA3.1(+) vector to the HepG2 and $\mathrm{HuH7}$ cells increases the expression of CCAT2 when compared with pcDNA3.1(+) empty vector. (B) Transfection of CCAT2 shRNA to the HepG2 and HuH7 cells decreases the expression of CCAT2 when compared with the negative control. Values are expressed as the mean \pm standard deviation. The experiments were performed in duplicate and repeated three times. ${ }^{*} \mathrm{P}<0.05$. CCAT2, colon cancer associated transcript 2; shRNA, small hairpin RNA.

in CCAT2 expression when compared with negative control (Fig. 2B). Furthermore, it was observed that the suppression of CCAT2 expression significantly inhibited the proliferation 
A

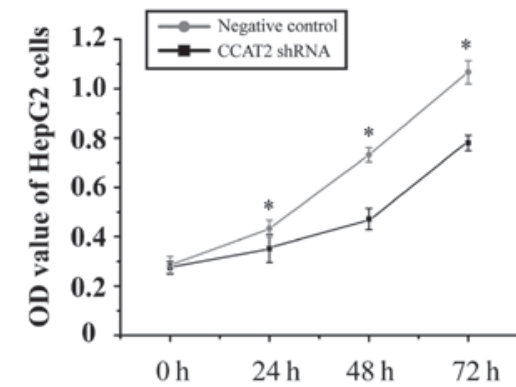

C

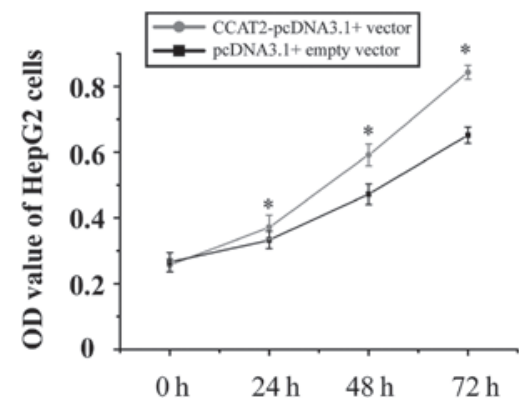

B

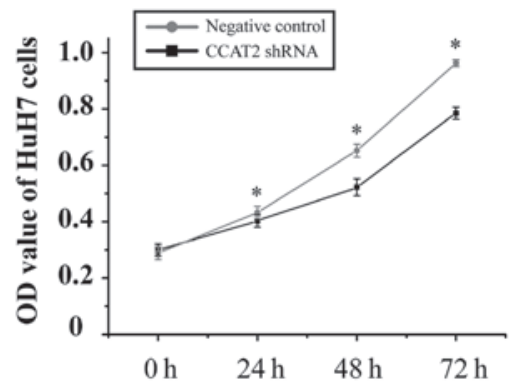

D

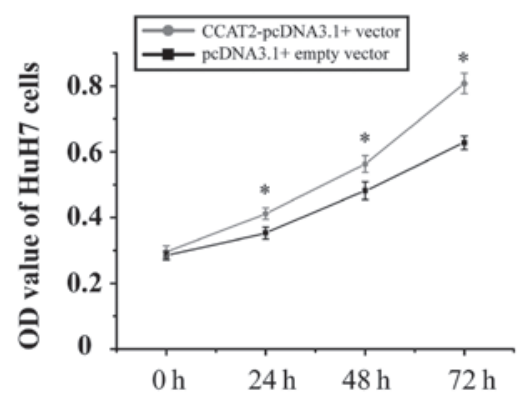

Figure 3. CCAT2 promotes the proliferation of HCC cells. MTT assay demonstrated significant inhibition of cell proliferation in CCAT2 shRNA transfected (A) HepG2 and (B) HuH7 cells when compared with the control. MTT assay demonstrated significant promotion of cell proliferation in CCAT2-pcDNA3.1(+) vector transfected (C) HepG2 and (D) HuH7 cells when compared with the empty vector. All experiments were performed three times and a representative picture is presented. " $\mathrm{P}<0.05$. OD, optical density; CCAT2, colon cancer associated transcript 2; HCC, hepatocellular carcinoma; MTT, 3-(4,5-dimethylthiazol-2-yl)-2,5-diphenyltetrazolium bromide; shRNA, small hairpin RNA.

of the HCC cells, while an increase in its expression promoted cell proliferation (Fig. 3). These results suggest that CCAT2 may function as an oncogene in the development of HCC.

CCAT2 promotes HCC cell migration. In order to identify the potential role of CCAT2 in HCC metastasis, the present study investigated the effect of CCAT2 on the migratory capacity of HCC cells. HepG2 and HuH7 cells were transfected with CCAT2 shRNA and negative control or CCAT2-pcDNA3.1(+) vector and pcDNA3.1(+) empty vector, and were then evaluated by cell migration assays. The results demonstrated that the suppression of CCAT2 expression significantly reduced the migration rate of the HepG2 and $\mathrm{HuH} 7$ cells when compared with the control (Fig. 4A). By contrast, the overexpression of CCAT2 significantly increased the migration rate of the HepG2 and $\mathrm{HuH} 7$ cells when compared with the control (Fig. 4B). These results indicate that CCAT2 functions as a oncogenic lncRNA and promotes the migration of HCC cells.

CCAT2 inhibits HCC cell apoptosis. It has been previously reported that lncRNAs serve a crucial role in cell apoptosis, particularly in the avoidance of apoptosis observed in cancer cells. To determine the impact of CCAT2 on HCC cell apoptosis, an enzyme-linked immunosorbent assay was utilized to measure the rate of apoptosis in the HCC cell lines. As presented in Fig. 5, the apoptosis rates of the HepG2 cells transfected with CCAT2 shRNA and the CCAT2-pcDNA3.1(+) vector were 28.5 vs. $2.3 \%$, respectively, and the apoptosis rates of the $\mathrm{HuH7}$ cells were 26.1 vs. $16.5 \%$, respectively; thus, demonstrating the upregulation of CCAT2-inhibited HCC cell apoptosis. When combined, the results provide strong evidence of CCAT2 functioning as a oncogene in HCC development.

\section{Discussion}

An increasing number of studies have demonstrated that the dysregulation of certain IncRNAs may contribute to tumorigenesis $(24,25)$. IncRNAs form a large family of highly-conserved molecules that regulate a wide array of cancer-associated genes, and may therefore be considered as a novel family of tumor suppressor genes and oncogenes $(24,25)$. The lncRNA CCAT2 is located on chromosome $8 \mathrm{q} 24.21$, and is differentially expressed in benign and malignant tumors (26-28). Previous studies have reported that CCAT2 is overexpressed in gastric and lung cancer $(21,22)$; however, to the best of our knowledge, the expression pattern and functional role of CCAT2 in HCC has not yet been elucidated.

HCC is the fifth most prevalent malignancy and accounts for $85-90 \%$ of all primary liver cancer cases (29). A number of studies have reported that IncRNAs serve an important function in the regulation of gene expression in cancer development (30-32). The dysregulation of lncRNAs has been identified in various types of cancer, including HOTAIR in ovarian and colorectal cancer, GAS5 in breast cancer and MALAT1 in prostate cancer (33-35). The dysregulation of IncRNAs has also been notably indicated in HCC, with H19, hepatocellular carcinoma up-regulated EZH2-associated lncRNA, microvascular invasion in HCC, hepatocellular carcinoma up-regulated lncRNA and MEG3 demonstrating dysregulation in HCC (36-38). Therefore, determination of the expression profile and function of aberrant lncRNAs in HCC would be particularly useful to further understand how lncRNAs assist the development of the disease.

In the present study, the expression of CCAT2 was analyzed in $50 \mathrm{HCC}$ tissues samples, with the results demonstrating that CCAT2 expression is higher in HCC tissues compared with paired adjacent non-tumoral tissues. Recent studies have 
A

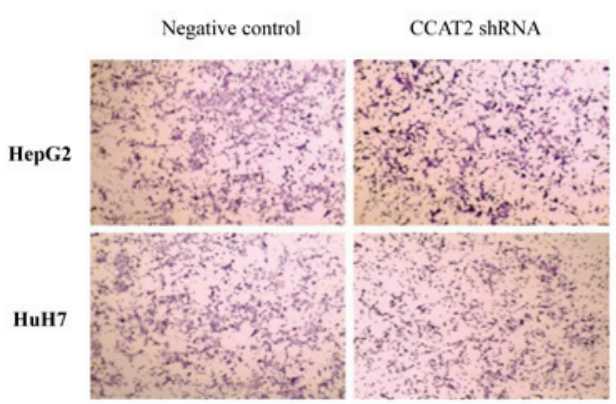

B

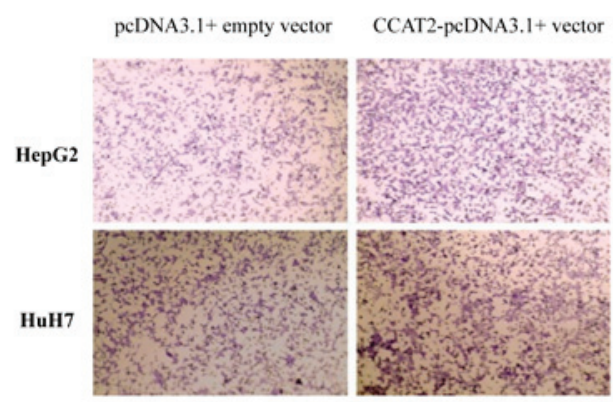

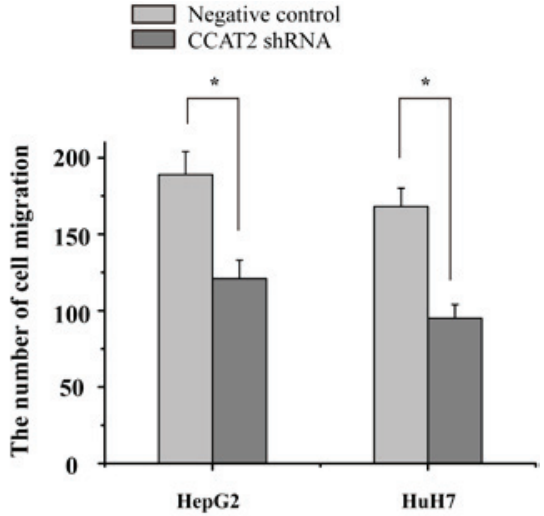

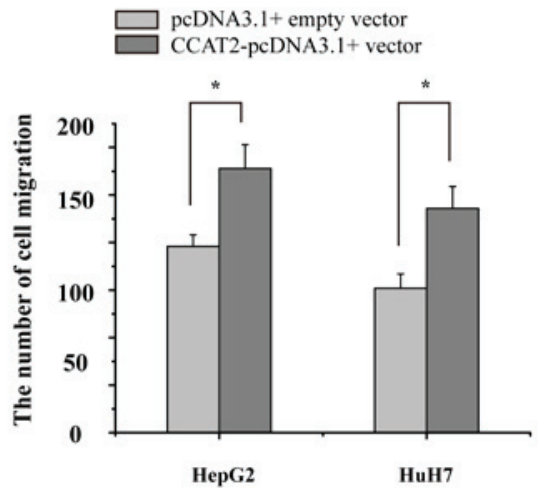

Figure 4. CCAT2 promotes HCC cell migration. (A) HepG2 and HuH7 cells transfected with CCAT2 shRNA or negative control. The suppression of CCAT2 expression significantly reduced the migration rate of the HCC cell lines when compared to the control. (B) HepG2 and HuH7 cells transfected with CCAT2-pcDNA3.1(+) vector or pcDNA3.1(+) empty vector. Overexpression of CCAT2 signifcantly increased the migration rate of the HCC cell lines when compared to the control. Values are expressed as the mean \pm standard deviation. Each experiment was repeated three times. "P<0.05.

A

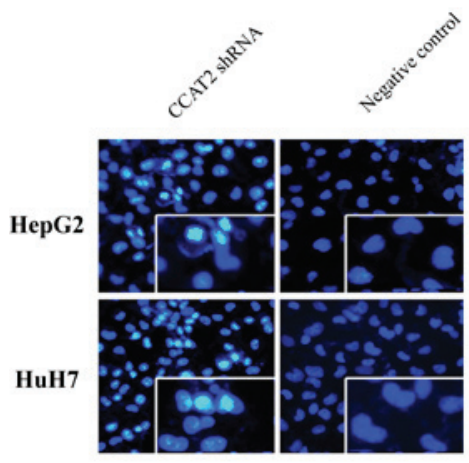

C

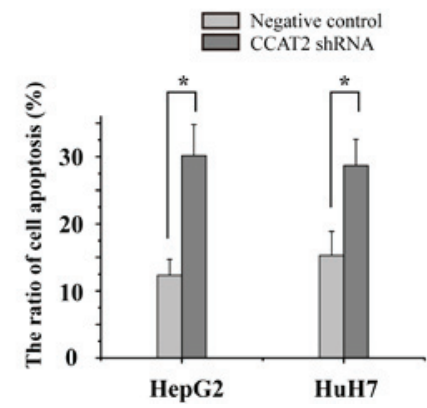

B

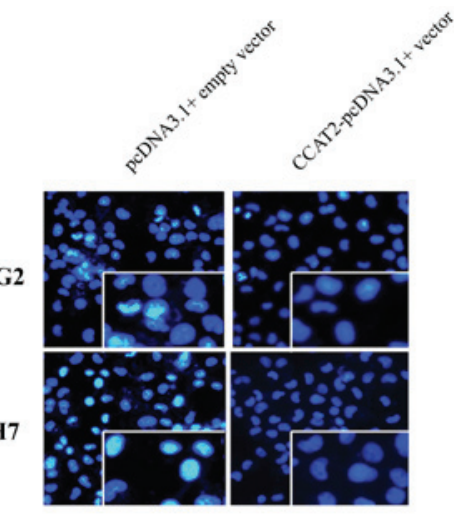

D

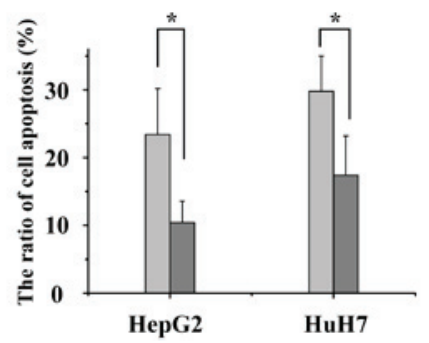

Figure 5. CCAT2 inhibits HCC cell apoptosis. (A) Apoptosis rates of HepG2 and HuH7 cells were increased after transfection with CCAT2 shRNA compared with the negative control. (B) Apoptosis rates of HepG2 and HuH7 cells were decreased after transfection with CCAT2-pcDNA3.1(+) vector compared with the pcDNA3.1(+) empty vector. Nuclei were counterstained with Hoechst 33258. Comparison of HepG2 and HuH7 cell apoptosis rates following transfection with (C) CCAT2 shRNA and the negative control or (D) the CCAT2-pcDNA3.1(+) vector and the pcDNA3.1(+) empty vector. Values are expressed as the mean \pm standard deviation. ${ }^{*} \mathrm{P}<0.05$. CCAT2, colon cancer associated transcript 2; shRNA, small hairpin RNA. 
reported that CCAT2 was upregulated in numerous types of cancer, which suggests that CCAT2 may function as a oncogene in cancer $(22,39)$. Previous studies have also demonstrated that CCAT2, a regulator of malignant cell progression, was associated with metastatic processes in human cancer. To elucidate the role of CCAT2 in the development of HCC, the present study performed HCC cell transfection. Restoration of CCAT2 in the HCC cells, as a result of transfection with the synthetic overexpression CCAT2-pcDNA3.1(+) vector, was demonstrated to promote proliferation and migration. In addition, the downregulation of CCAT2 in the HCC cells inhibited the proliferation and migration of the HCC cells. The results of the present study suggest that CCAT2 serves a crucial role in HCC cell proliferation, migration and apoptosis.

In conclusion, the current study demonstrated that CCAT2 was upregulated in HCC tissue, and indicated that this lncRNA may function in $\mathrm{HCC}$ development through the dysregulation of cellular migration, proliferation and apoptosis. CCAT2 is a promising biomarker and/or a therapeutic target for $\mathrm{HCC}$, with further study required to elucidate the underlying molecular mechanisms of CCAT2 in HCC development.

\section{References}

1. Lin L, Liang H, Wang Y, Yin X, Hu Y, Huang J, Ren T, Xu H, Zheng L and Chen X: MicroRNA-141 inhibits cell proliferation and invasion and promotes apoptosis by targeting hepatocyte nuclear factor-3 $\beta$ in hepatocellular carcinoma cells. BMC Cancer 14: 879, 2014.

2. Block TM, Mehta AS, Fimmel CJ and Jordan R: Molecular viral oncology of hepatocellular carcinoma. Oncogene 22: 5093-5107, 2003.

3. Braconi C, Valeri N, Kogure T, Gasparini P, Huang N, Nuovo GJ, Terracciano L, Croce CM and Patel T: Expression and functional role of a transcribed noncoding RNA with an ultraconserved element in hepatocellular carcinoma. Proc Natl Acad Sci USA 108: 786-791, 2011.

4. Li G, Zhang H, Wan X, Yang X, Zhu C, Wang A, He L, Miao R, Chen $\mathrm{S}$ and Zhao H: Long noncoding RNA plays a key role in metastasis and prognosis of hepatocellular carcinoma. Biomed Res Int 2014: 780521, 2014

5. Cui M, Zheng M, Sun B, Wang Y, Ye L and Zhang X: A long noncoding RNA perturbs the circadian rhythm of hepatoma cells to facilitate hepatocarcinogenesis. Neoplasia 17: 79-88, 2015.

6. Dong P, Yu F, Fan X, Lin Z, Chen Y and Li J: Inhibition of ATIR by shRNA prevents collagen synthesis in hepatic stellate cells. Mol Cell Biochem 344: 195-202, 2010.

7. Gomes AQ, Nolasco S and Soares H: Non-coding RNAs: Multi-tasking molecules in the cell. Int J Mol Sci 14: 16010-16039, 2013.

8. Gao SM, Xing CY, Chen CQ, Lin SS, Dong PH and Yu FJ: miR-15a and miR-16-1 inhibit the proliferation of leukemic cells by down-regulating WT1 protein level. J Exp Clin Cancer Res 30: 110, 2011.

9. Yu FJ, Dong PH, Fan XF, Lin Z, Chen YP and Li J: Down-regulation of angiotensin II by shRNA reduces collagen synthesis in hepatic stellate cells. Int J Mol Med 25: 801-806, 2010.

10. Chen SL, Zheng MH, Yang T, Song M and Chen YP: Disparate profiles of dys-regulated miRNAs in activated hepatic stellate cells. Hepatology 57: 1285-1286, 2013.

11. Kitagawa M, Kotake Y and Ohhata T: Long non-coding RNAs involved in cancer development and cell fate determination. Curr Drug Targets 13: 1616-1621, 2012.

12. Yoon JH, Abdelmohsen K, Srikantan S, Yang X, Martindale JL, De S, Huarte M,Zhan M,Becker KG and Gorospe M: LincRNA-p21 suppresses target mRNA translation. Mol Cell 47: 648-655, 2012.

13. Yoon JH, Abdelmohsen K and Gorospe M: Posttranscriptional gene regulation by long noncoding RNA. J Mol Biol 425: 3723-3730, 2013.

14. Zhang Y, Yang L and Chen LL: Life without A tail: New formats of long noncoding RNAs. Int J Biochem Cell Biol 54: 338-349, 2014.
15. Nadal-Ribelles M, Solé C, Xu Z, Steinmetz LM, de Nadal E and Posas F: Control of Cdc28 CDK1 by a stress-induced 1ncRNA. Mol Cell 53: 549-561, 2014.

16. Yang F, Yi F, Han X, Du Q and Liang Z: MALAT-1 interacts with hnRNP C in cell cycle regulation. FEBS Lett 587: 3175-3181, 2013.

17. Shi X, Sun M, Liu H, Yao Y and Song Y: Long non-coding RNAs: A new frontier in the study of human diseases. Cancer Lett 339: 159-166, 2013

18. Lai MC, Yang Z, Zhou L, Zhu QQ, Xie HY, Zhang F, Wu LM, Chen LM and Zheng SS: Long non-coding RNA MALAT-1 overexpression predicts tumor recurrence of hepatocellular carcinoma after liver transplantation. Med Oncol 29: 1810-1816, 2012.

19. Ishibashi M, Kogo R, Shibata K, Sawada G, Takahashi Y, Kurashige J, Akiyoshi S, Sasaki S, Iwaya T, Sudo T, et al: Clinical significance of the expression of long non-coding RNA HOTAIR in primary hepatocellular carcinoma. Oncol Rep 29: 946-950, 2013

20. Braconi C, Kogure T, Valeri N, Huang N, Nuovo G, Costinean S, Negrini M, Miotto E, Croce CM and Patel T: microRNA-29 can regulate expression of the long non-coding RNA gene MEG3 in hepatocellular cancer. Oncogene 30: 4750-4756, 2011.

21. Wang CY, Hua L, Yao KH, Chen JT, Zhang JJ and Hu JH: Long non-coding RNA CCAT2 is up-regulated in gastric cancer and associated with poor prognosis. Int J Clin Exp Pathol 8: 779-785, 2015.

22. Qiu M, Xu Y, Yang X, Wang J, Hu J, Xu L and Yin R: CCAT2 is a lung adenocarcinoma-specific long non-coding RNA and promotes invasion of non-small cell lung cancer. Tumour Biol 35: 5375-5380, 2014

23. Schmittgen TD and Livak KJ: Analyzing real-time PCR data by the comparative C(T) method. Nat Protoc 3: 1101-1108, 2008.

24. Deng R, Liu B, Wang Y, Yan F, Hu S, Wang H, Wang T, Li B, Deng X, Xiang S, et al: High expression of the newly found long noncoding RNA Z38 promotes cell proliferation and oncogenic activity in breast cancer. J Cancer 7: 576-586, 2016.

25. Deng W, Wang J, Zhang J, Cai J, Bai Z and Zhang Z: TET2 regulates LncRNA-ANRIL expression and inhibits the growth of human gastric cancer cells. IUBMB Life 68: 355-364, 2016.

26. Wang J, Qiu M, Xu Y, Li M, Dong G, Mao Q, Yin R and $\mathrm{Xu}$ L: Long noncoding RNA CCAT2 correlates with smoking in esophageal squamous cell carcinoma. Tumour Biol 36: 5523-5528, 2015.

27. Redis RS, Sieuwerts AM, Look MP, Tudoran O, Ivan C, Spizzo R, Zhang X, de Weerd V, Shimizu M, Ling H, et al: CCAT2, a novel long non-coding RNA in breast cancer: Expression study and clinical correlations. Oncotarget 4: 1748-1762, 2013.

28. Ling H, Spizzo R, Atlasi Y, Nicoloso M, Shimizu M, Redis RS, Nishida N, Gafà R, Song J, Guo Z, et al: CCAT2, a novel noncoding RNA mapping to $8 \mathrm{q} 24$, underlies metastatic progression and chromosomal instability in colon cancer. Genome Res 23: 1446-1461, 2013.

29. Zhu J, Liu S, Ye F, Shen Y, Tie Y, Zhu J, Jin Y, Zheng X, Wu Y and Fu H: The long noncoding RNA expression profile of hepatocellular carcinoma identified by microarray analysis. PLoS One 9: e101707, 2014.

30. Pan YF, Feng L, Zhang XQ, Song LJ, Liang HX, Li ZQ and Tao FB: Role of long non-coding RNAs in gene regulation and oncogenesis. Chin Med J (Engl) 124: 2378-2383, 2011.

31. Li J, Meng H, Bai Y and Wang K: Regulation of lncRNA and its role in cancer metastasis. Oncol Res 23: 205-217, 2016.

32. Adams BD, Anastasiadou E, Esteller M, He L and Slack FJ: The inescapable influence of noncoding RNAs in cancer. Cancer Res 75: 5206-5210, 2015.

33. Faghihi MA, Modarresi F, Khalil AM, Wood DE, Sahagan BG, Morgan TE, Finch CE, St Laurent G III, Kenny PJ and Wahlestedt C: Expression of a noncoding RNA is elevated in Alzheimer's disease and drives rapid feed-forward regulation of beta-secretase. Nat Med 14: 723-730, 2008.

34. Gupta RA, Shah N, Wang KC,Kim J, Horlings HM, Wong DJ, Tsai MC, Hung T, Argani P, Rinn JL, et al: Long non-coding RNA HOTAIR reprograms chromatin state to promote cancer metastasis. Nature 464: 1071-1076, 2010.

35. Mourtada-Maarabouni M, Pickard MR, Hedge VL, Farzaneh F and Williams GT: GAS5, a non-protein-coding RNA, controls apoptosis and is downregulated in breast cancer. Oncogene 28: 195-208, 2009 
36. Yuan SX, Yang F, Yang Y, Tao QF, Zhang J, Huang G, Yang Y, Wang RY, Yang S, Huo XS, et al: Long noncoding RNA associated with microvascular invasion in hepatocellular carcinoma promotes angiogenesis and serves as a predictor for hepatocellular carcinoma patients' poor recurrence-free survival after hepatectomy. Hepatology 56: 2231-2241, 2012.

37. Matouk IJ, DeGroot N, Mezan S, Ayesh S, Abu-lail R, Hochberg A and Galun E: The H19 non-coding RNA is essential for human tumor growth. PLoS One 2: e845, 2007.
38. Yang F, Zhang L, Huo XS, Yuan JH, Xu D, Yuan SX, Zhu N, Zhou WP, Yang GS, Wang YZ, et al: Long noncoding RNA high expression in hepatocellular carcinoma facilitates tumor growth through enhancer of zeste homolog 2 in humans. Hepatology 54: 1679-1689, 2011.

39. Chen X, Liu L and Zhu W: Up-regulation of long non-coding RNA CCAT2 correlates with tumor metastasis and poor prognosis in cervical squamous cell cancer patients. Int J Clin Exp Pathol 8: 13261-13266, 2015. 